\title{
Studies on taxonomy and distribution of Acridoidea (Orthoptera) of Bihar, India
}

\author{
Mohd. Kamil Usmani ${ }^{1} \&$ Md. Rashid Nayeem ${ }^{2}$ \\ 1,2 Section of Entomology, Department of Zoology, Aligarh Muslim University, Aligarh, Uttar Pradesh 202002, India \\ Email: ${ }^{1}$ rashidnayeem48@gmail.com (corresponding author), ${ }^{2}$ usmanikamil94@gmail.com
}

Date of publication (online): 26 October 2012 Date of publication (print): 26 October 2012 ISSN 0974-7907 (online) | 0974-7893 (print)

Editor: R.K. Avasthi

\section{Manuscript details:}

Ms \# 03010

Received 16 November 2011

Final received 10 September 2012

Finally accepted 21 September 2012

Citation: Usmani, M.K. \& M.R. Nayeem (2012). Studies on taxonomy and distribution of Acridoidea (Orthoptera) of Bihar, India. Journal of Threatened Taxa 4(13): 3190-3204.

Copyright: $\odot$ Mohd. Kamil Usmani \& Md. Rashid Nayeem 2012. Creative Commons Attribution 3.0 Unported License. JoTT allows unrestricted use of this article in any medium for non-profit purposes, reproduction and distribution by providing adequate credit to the authors and the source of publication.

Author Details: See end of this artilce.

Author Contribution: MRN collected, identified and described the specimens. MKU confirmed the identification, and reviewed the entire manuscript.

Acknowledgements: We extend our gratitude to the Department of Science \& Technology, New Delhi for providing financial assistance during the tenure of a major research project (Ref. No. SR/SO/AS 32/2008) being carried out on Biosystematics and Biodiversity of Acridoidea (Orthoptera) in northern India. Thanks are also due to Prof. Irfan Ahmad, Chairman, Department of Zoology, Aligarh Muslim University, Aligarh for providing necessary facilities.
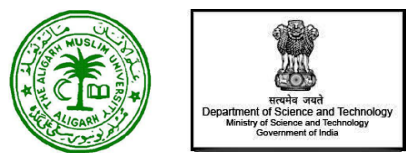

ZooBank urn:Isid:zoobank.org:pub:89A1DADD -0DBF-4C6B-B59A-39B4ED58D75F

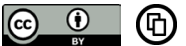

OPEN ACGESS | FREE DOWNLOAD
Abstract: Thirty seven species of locusts and grasshoppers representing 26 genera, four tribes and 12 subfamilies belonging to the families Pyrgomorphidae, Catantopidae and Acrididae are reported from different localities of Bihar. Their distinguishing characters and bio-ecological data are provided along with keys to tribes and subfamilies. This paper comprising of distribution and field observation along with taxonomy of Acridoid fauna is the first of its kind from the state.

Keywords: Acridoidea, Bihar, biodiversity, distribution, Orthoptera, taxonomy.

\section{INTRODUCTION}

Acridoidea is one of the most sought after superfamilies of the order Orthoptera. The order Orthoptera consists of insects with paurometabolous or incomplete metamorphosis, including grasshoppers, crickets and locusts. Many insects in this order produce sound (known as stridulation) by rubbing their wings or their legs against each other, the wings or legs contain rows of corrugated bumps. They are also well adapted for flight since both direct and indirect muscles work together during flight movements thus explaining the reason that these insects can cover long distances during swarming conditions that mainly result from overcrowding and scarcity of food.

Acridoidea is an important Superfamily of the suborder Caelifera (Short-horned Grasshoppers with three segmented tarsi and a short ovipositor), the others are Tridactyloidea, Tetrigoidea and Eumastacoidea. Tetrigoidea is easily distinguishable from Acridoidea by the elongated pronotum, usually extending beyond the end of the body; by the absence of an arolium between the claws and the two-segmented tarsi of the fore and middle legs. The other superfamilies of Caelifera are easily recognizable at sight and are not frequently encountered. Superfamily Acridoidea has shown maximum diversity and divided into various families of which the families Acrididae, Catantopidae and Pyrgomorphidae are widely distributed in India.

A notable taxonomical work on Acrididae was made by Kirby (1914) in the series 'Fauna of British India' and he divided the family Acrididae into eight subfamilies. Uvarov $(1921,1924,1927,1942)$ studied in detail the Indian Acrididae. Agarwala (1952) contributed some studies on female copulatory structures in relation to oviposition sites while Roonwal (1956) contributed some studies on the nymphal structures and ecology on Acrididae. Dirsh (1965, 1975), Tandon (1975, 1976), Bhowmik (1985), Shishodia (1987, 1997, 1999), Shishodia et al. (2010), Usmani \& Shafee 
(1980, 1982, 1983, 1984, 1985a,b, 1990), Kumar \& Virktamath (1991a,b), Hazra et al. (1993), Usmani (2005) have contributed works on the taxonomy of this group. More recently, Tandon \& Khera (1978), Julka et al. (1982), Dey \& Hazra (2003), Nayeem \& Usmani $(2011,2012)$ have worked on the taxonomy as well as on the ecology of this group.

The species represented in this region are briefly described. In the present study the authors uphold recent workers in classifying Acridoidea with a few generally accepted changes. The superfamily Acridoidea is understood here in the same sense as by Uvarov (1966). There are very few reports on the taxonomy of Acridoidea from this region. The latest work has been carried out by Shishodia et al. (2010). Keeping in view the above facts, the present work is aimed at studying one of the superfamilies of Orthoptera which is widely distributed and shows a very high degree of biological diversity.

Bihar is one of the most important eastern states of India and has a notified forest area of $6,764.14 \mathrm{~km}^{2}$ and is a vast stretch of fertile plain that consists of a thick alluvial mantle of drift origin overlying in most parts. The soil is mainly young loam rejuvenated every year by constant deposition of silt, clay and sand brought by different streams. It is mainly drained by the Ganga River, including its northern tributaries Gandak and Kosi that regularly flood parts of the Bihar plains. The state lies between $25^{\circ} 8^{\prime}-27^{0} 31^{\prime} \mathrm{N}$ and $83^{\circ} 20^{\prime}-88^{\circ} 17^{\prime} \mathrm{E}$ occupying an area of $94,163 \mathrm{~km}^{2}$. The average elevation of the state is $52.73 \mathrm{~m}$ above sea level. Topographically, Bihar can be grouped into three regions: the northern mountainous region, the Indo-Gangetic Plain and the southern plateau.

This fertile alluvial tract is the product of various Himalayan and peninsular rivers like Gandak, Budhi Gandak, Koshi, Mahananda, Bagmati, Gogra and Son and other small rivers and rivulets. The Gangetic plains of Bihar is divided into north and south by the Ganga River which flows through it. Being located between 25-27 ${ }^{0}$ North latitude, the climate of Bihar is mostly subtropical. The average temperature in summer is 35-40 degrees C during March-May. April and June are the hottest months of the year. The average temperature in winter is $5-10$ degrees $\mathrm{C}$ during December-January. Bihar gets its maximum rainfall during the south-west monsoon from June to September. The average rainfall of Bihar is around
$120 \mathrm{~cm}$. The natural vegetation of Bihar is moist deciduous forests. These forests are mostly found in the northern and southern parts of the state.

Agriculture is the backbone of Bihar's economy employing $81 \%$ of the workforce and generating nearly $42 \%$ of the State Domestic Product. The percentage of population employed in agriculture in Bihar is much higher than the national average. The gross and net sown area in the state is estimated at $80,000 \mathrm{~km}^{2}$ and $56,000 \mathrm{~km}^{2}$, respectively. The principal crops are paddy, wheat, pulses, maize, potato, sugarcane, oil seeds, tobacco and jute. Rice, wheat and maize are the major crops. During the survey it was concluded (based on field observation) that at an average, agricultural fields of paddy and wheat have shown maximum infestation of Aiolopus sp. followed by Oxya sp. and Hieroglyphus sp., the grasslands had Spathosternum and Tristria as commonly found genera, shrubs and bushy patches and plantations of pulses mainly arhar were home to Catantops sp., Xenocatantops sp. and Chrotogonous sp. while areas of wild vegetation had Oedipoda, Locusta, Catantops and Eyprepocnemis in common.

If we talk about the field observation it may be concluded that the majority of the areas of southern and southwestern Bihar had more infestation as compared to the northern and northeastern regions of the state. The insects were observed to be less active during the morning and evening hours as compared to the sunlit hours of the day. At dawn hours the concentration of grasshoppers was more in the sunlit patches of the fields and one could rarely find them in shadowed areas. In maize and sugarcane fields especially,their concentration was more above the ground i.e. on plant parts rather than on the ground in grasses, while in the case of vegetables they were more in numbers on the ground in grasses and very few were spotted resting on the plant parts.

In the present study 37 species representing 29 genera belonging to three families, 12 subfamilies and four tribes have been recorded from various regions of Bihar (Table 1). The specimens studied in this work are deposited in the Department of Zoology, Aligarh Muslim University, Uttar Pradesh, India. 


\section{MATERIAL AND METHODS}

About 277 specimens of grasshoppers were collected from various agricultural pastural areas of Bihar and forest habitats. This served as the basis for the present critical study. A complete record was also maintained indicating the reference number, locality, date of collection and name of host plants etc.

\section{(I) Collection of adult grasshoppers}

The authors surveyed various agricultural areas of Bihar during the period 2009-2010 for the collection of grasshoppers and locusts. They were caught by hand, by forceps, and by the ordinary aerial insect net. The net was used for catching insects individually or by sweeping on grasses, bushes and other vegetables. Since some acridoids live on trees, it is sometimes highly rewarding to investigate the branches of trees. Attempts were made to collect the specimens from their host plants as well as those attracted to light during the night. They were captured on different dates in different months from various crops. Different parts of crops were examined. Attention was also given to fruits and vegetables. The collected specimens were killed in cyanide bottles.

\section{(II) Preparations for morphological studies}

Dry mounts were also prepared for better understanding of certain characters like size, colour, texture etc. For this purpose, the specimens were first relaxed, stretched and later they were pinned and labeled properly. Permanent collections of pinned specimens were kept in store boxes and cabinets for further studies on their morphological structures.

\section{(III) Preparations for genitalic studies}

For a detailed study of the various components of genitalia, permanent slides were prepared and examined under a microscope in order to conduct a detailed study of the genitalic structures. Drawings were initially made with the help of camera lucida. Details were filled in by conventional microscope examination.
Table 1. Geographic coordinates of collection sites

\begin{tabular}{|c|c|c|}
\hline S.No. & Site & Coordinates \\
\hline 1 & Ara & $25.3400^{\circ} \mathrm{N} \& 84.4000^{\circ} \mathrm{E}$ \\
\hline 2 & Araria & $26.1500^{\circ} \mathrm{N} \& 87.5200^{\circ} \mathrm{E}$ \\
\hline 3 & Aurangabad & $24.7500^{\circ} \mathrm{N} \& 84.3700^{\circ} \mathrm{E}$ \\
\hline 4 & Banka & $24.8800^{\circ} \mathrm{N} \& 86.9200^{\circ} \mathrm{E}$ \\
\hline 5 & Begusarai & $25.4200^{\circ} \mathrm{N} \& 86.1300^{\circ} \mathrm{E}$ \\
\hline 6 & Bettiah & $26.8000^{\circ} \mathrm{N} \& 84.5000^{\circ} \mathrm{E}$ \\
\hline 7 & Bhabua & $25.0500^{\circ} \mathrm{N} \& 83.6200^{\circ} \mathrm{E}$ \\
\hline 8 & Bhagalpur & $25.1500^{\circ} \mathrm{N} \& 87.0200^{\circ} \mathrm{E}$ \\
\hline 9 & Bihar Sharif & $25.2100^{\circ} \mathrm{N} \& 85.2000^{\circ} \mathrm{E}$ \\
\hline 10 & Buxar & $25.3338^{\circ} \mathrm{N} \& 83.5850^{\circ} \mathrm{E}$ \\
\hline 11 & Chhapra & $25.7848^{\circ} \mathrm{N} \& 84.7274^{\circ} \mathrm{E}$ \\
\hline 12 & Darbhanga & $26.1700^{\circ} \mathrm{N} \& 85.9000^{\circ} \mathrm{E}$ \\
\hline 13 & Gaya & $24.7800^{\circ} \mathrm{N} \& 85.0000^{\circ} \mathrm{E}$ \\
\hline 14 & Gopalganj & $26.4700^{\circ} \mathrm{N} \& 84.4300^{\circ} \mathrm{E}$ \\
\hline 15 & Hajipur & $25.6800^{\circ} \mathrm{N} \& 85.2200^{\circ} \mathrm{E}$ \\
\hline 16 & Jamui & $24.9200^{\circ} \mathrm{N} \& 86.2200^{\circ} \mathrm{E}$ \\
\hline 17 & Jehanabad & $25.1300^{\circ} \mathrm{N} \& 84.5900^{\circ} \mathrm{E}$ \\
\hline 18 & Katihar & $25.5300^{\circ} \mathrm{N} \& 87.5800^{\circ} \mathrm{E}$ \\
\hline 19 & Khagaria & $25.5000^{\circ} \mathrm{N} \& 86.4800^{\circ} \mathrm{E}$ \\
\hline 20 & Kishanganj & $25.7000^{\circ} \mathrm{N} \& 86.9500^{\circ} \mathrm{E}$ \\
\hline 21 & Luckeesarai & $25.1833^{\circ} \mathrm{N} \& 86.0833^{\circ} \mathrm{E}$ \\
\hline 22 & Madhepura & $25.9167^{\circ} \mathrm{N} \& 86.7833^{\circ} \mathrm{E}$ \\
\hline 23 & Madhubani & $26.3700^{\circ} \mathrm{N} \& 86.0800^{\circ} \mathrm{E}$ \\
\hline 24 & Motihari & $26.6500^{\circ} \mathrm{N} \& 84.9200^{\circ} \mathrm{E}$ \\
\hline 25 & Munger & $25.3800^{\circ} \mathrm{N} \& 86.4700^{\circ} \mathrm{E}$ \\
\hline 26 & Muzaffarpur & $26.1200^{\circ} \mathrm{N} \& 85.4000^{\circ} \mathrm{E}$ \\
\hline 27 & Nawada & $24.8800^{\circ} \mathrm{N} \& 85.5300^{\circ} \mathrm{E}$ \\
\hline 28 & Patna & $25.6155^{\circ} \mathrm{N} \& 85.1355^{\circ} \mathrm{E}$ \\
\hline 29 & Purnia & $25.7800^{\circ} \mathrm{N} \& 87.4700^{\circ} \mathrm{E}$ \\
\hline 30 & Rajgir & $25.0300^{\circ} \mathrm{N} \& 85.4200^{\circ} \mathrm{E}$ \\
\hline 31 & Saharsa & $25.8800^{\circ} \mathrm{N} \& 86.6000^{\circ} \mathrm{E}$ \\
\hline 32 & Samastipur & $25.8500^{\circ} \mathrm{N} \& 85.7800^{\circ} \mathrm{E}$ \\
\hline 33 & Sasaram & $24.9500^{\circ} \mathrm{N} \& 84.0300^{\circ} \mathrm{E}$ \\
\hline 34 & Sitamarhi & $26.6000^{\circ} \mathrm{N} \& 85.4800^{\circ} \mathrm{E}$ \\
\hline 35 & Siwan & $25.1300^{\circ} \mathrm{N} \& 83.8800^{\circ} \mathrm{E}$ \\
\hline 36 & Supaul & $25.9300^{\circ} \mathrm{N} \& 86.2500^{\circ} \mathrm{E}$ \\
\hline
\end{tabular}

\section{RESULTS}

\section{Taxonomic Account}

Superfamily: Acridoidea Latreille, 1802

The Superfamily Acridoidea is represented by three families. 
A. Family: Pyrgomorphidae Brunner, 1874

Tribe: Atractomorphini Bolivar, 1884

1. Atractomorpha psittacina (Haan, 1842)

Diagnostic characters: Small to medium sized body, slender in shape, filiform antennae inserted in front of lateral ocellus, fastigial furrow present, eyes elongate oval, lateral margins of head and pronotum tuberculated, lateral pronotal lobe with a membranous area in metazona, prosternal process antero-posteriorly compressed.

Material examined: 1 male, 23.x.2010, on underlying grasses in vegetable field, Chhapra, Saran; 1 male, 2 females, 25.x.2010, on grasses, Motihari, Purba Champaran.

Morphometry: (length in mm). Male: Body 23.85, Tegmina 18.2, Hind femur 9.5, Pronotum 2.55. Female: Body 35.2, Tegmina 25.0, Hind femur 11.75, Pronotum 6.3

Remarks: Commonly found in grasses of vegetable field but may also be found in cereals.

Natural enemies: No natural enemies recorded.

Distribution: Bihar, Jharkhand, Uttar Pradesh.

\section{Atractomorpha sinensis (Bolivar, 1905)}

Diagnostic characters: Body medium sized and slender, tegmina fully developed, tapered and pointed, eyes comparatively short, roundish oval, lateral pronotal lobe with a membranous area in metzona, fastigium of vertex broader and flatter, rose colour at the base of hind wings.

Material examined: 3 females, 24.x.2010, on grasses, Gopalganj; 1 female, 27.x.2010, on grasses, Hajipur, Vaishali; 1 female, 26.x.2010, on grasses, Samastipur; 1 female, 28.x.2010, on grasses, Supaul

Morphometry: (length in mm). Female: Body 28.6, Tegmina 21.0, Hind femur 13.85, Pronotum 6.0

Remarks: Has great camouflage potential and thereby tough to spot in its habitat.

Natural enemies: No natural enemies recorded.

Distribution: Bihar.

\section{Tribe: Poekilocerini Burmeister, 1838}

\section{Poekilocerus pictus (Fabricius, 1775)}

Diagnostic characters: This species of Poekilocerus can be distinguished from other species by its blueblack ringed antennae with black and yellow pattern beyond the basal third of sub-interupted transverse yellow bands, pronotum impress-punctate, rounded behind, the hind sulcus placed just behind the middle. Material Examined: 1 female, 24.vi.2009, on Calotropis procera, Banka.

Morphometry: (length in mm). Female: Body 54.0, Tegmina 33.2, Hind femur 20.9, Pronotum 4.0.

Remarks: The preferred food plant is Calotropis procerca (Ait.) which favour sandy soil and semi-arid conditions. The readiness to accept alternative food plants has enabled Poekilocerus to survive in some areas where Calotropis is scarce or even absent. This is the most mobile member of the genus in which both sexes especially the females have proportionately longer wings.

Natural enemies: The praying mantis Mantis religiosa is a predator and the dipterous parasite Blaesoxipha sp. has been recorded to cause nearly $11 \%$ mortality of hoppers.

Distribution: Himachal Pradesh, Chhattisgarh, Andhra Pradesh, Rajasthan, Bihar.

\section{Tribe: Chrotogonini Bolivar, 1904}

\section{Chrotogonus trachypterus (Blanchard, 1836)}

Diagnostic characters: Body brown, rugose and tuberculate; head short and broad; antennae 11-segmented; pronotum short, broad with small tubercles; sternum yellowish; tegmina reaching near to the tip of abdomen, covered with numerous prominent nodules, wings nearly as long as the tegmen; hind femur as long as the abdomen; hind tibia with seven external and nine internal spines; abdomen brown above, pale beneath, without darkish spots, but with darkish tinge.

Material examined: 1 female, 23.vi.2009, on grasses, Khagaria; 1 female, 16.vi.2009, on paddy, Gaya; 2 females, 26.vi.2009, on arhar, Katihar; 1 female, 26.x.2010, on grasses, Samastipur; 1 female, 4.vi.2010, on grasses, Bettiah, Paschim Champaran.

Morphometry: (length in mm). Female: Body 15.0, Tegmina 5.2, Hind femur 6.8, Pronotum 3.25

Remarks: Body colour matches with the soil and can be commonly spotted in ploughed fields and roadside grasses.

Natural enemies: The hymenopterans Scelio aegyptiacus Priesner and $S$. hieroglyphi Timb. were recorded to parasitize the eggs by Ahmed et al. (1973).

Distribution: Andhra Pradesh, Assam, Bihar, Delhi, Gujarat, Haryana, Himachal Pradesh, Jammu and 
Kashmir, Madhya Pradesh, Maharashtra, Meghalaya, Orissa, Punjab, Rajasthan, Uttar Pradesh, West Bengal.

\section{B. Family: Catantopidae Brunner, 1893 Subfamily: Oxyinae Brunner, 1893}

\section{Oxya japonica japonica (Thunberg, 1824)}

Diagnostic characters: Antennae as long as or slightly longer than head and pronotum together. Lateral longitudinal ridges on ventral surface of female sub genital plate without spines except at apices. Ovipositor valves with short dents. Posterior ventral basivalvular sclerite with a large spine on its inner ventral margin, male cercus with sub-acute or truncate apex.

Material examined: 1 male, 1 female, 13.vi.2009, on paddy, Sarsaram, Rohtas; 2 females, 14.vi.2009, on paddy, Aurangabad; 1 female, 16.vi.2009, on paddy, Gaya; 26 females, 16.iv.2010, on wheat, Araria.

Morphometry: (Length in $\mathrm{mm}$ ). Male: Body 11.7, Tegmina 19.9, Hind femur 10.7, Pronotum 7.8. Female: Body 14.9, Tegmina 23.5, Hind femur 14.9, Pronotum 9.0

Remarks: This sub-species is widely distributed in India and Indo-Malayan region. It is a major pest of paddy crop.

Natural enemies: No natural enemies are recorded.

Distribution: Uttar Pradesh, Rajasthan, Tamil Nadu, Tripura, West Bengal, Gujarat, Bihar, Assam, Manipur, Karnataka, Kerala, Punjab.

\section{Oxya hyla hyla (Serville, 1831)}

Diagnostic characters: Body of medium size, antennae filiform, longer than, as long as, or shorter than head and pronotum together; fastigium of vertex short, without mid-longitudinal carinula, frontal ridge sulcate, dorsum of pronotum slightly flattened, crossed by three transverse sulci, median carina weak, lateral carinae absent, metazona shorter than prozona, posterior margin rounded or obtusely angular. Ovipositor valves with long hook like dents posterior ventral basivalvular sclerites with very small spinelets on its inner ventral margin. Male circus with subacute or truncate apex.

Material examined: 2 females, 24.x.2010, on grasses, Gopalganj; 1 female, 24.vi.2009, on paddy, Banka; 6 females, 20.xi.2010, on paddy, Araria; 1 female, 13.vi.2009, on paddy, Sarsaram, Rohtas.
Morphometry: (length in mm). Female: Body 13.8, Tegmina 22.2, Hind femur 13.4, Pronotum 8.2.

Remarks: Reputed pest of paddy.

Natural enemies: No natural enemies recorded.

Distribution: Punjab, Haryana, Bihar, Uttar Pradesh, Uttarakhand, Tamil Nadu, West Bengal, Assam, Meghalaya, Manipur.

\section{Oxya fuscovittata (Marschall, 1836)}

Diagnostic characters: Posterior margin of female subgenital plate almost straight and smooth. Male supra anal plate with a tubercles on each side of median apical process, cercus laterally much compressed and of uniform width.

Material examined: 1 female, 20.xi.2010, on paddy, Araria.

Morphometry: (length in mm). Female: Body 14.7, Tegmina 22.8, Hind femur 14.2, Pronotum 8.8.

Remarks: Pest of Paddy but also found in grasslands.

Natural enemies: No natural enemies recorded.

Distribution: Uttar Pradesh, Uttarakhand, West Bengal, Bihar, Jharkhand, Punjab.

\section{Oxya velox (Fabricius, 1787)}

Diagnostic characters: Posteriorventral basivalvular sclerites of ovipositor without any well defined spines on its lower inner margin. Median pair of spines on posterior margin of subgenital plate set wider apart. Male circus conical with subacute apex.

Material examined: 2 females, 25.vi.2009, on paddy saplings, Bhagalpur; 1 female, 25.x.2010, on grasses, Motihari, Purba Champaran.

Morphometry: (length in mm). Female: Body 13.7, Tegmina 23.05, Hind femur 14.65, Pronotum 8.85 .

Remarks: Commonly spotted in paddy saplings rather than the crop.

Natural enemies: Red mite Eutrombidium trigonum also observed parasitizing this species.

Distribution: Bihar, Uttar Pradesh, Arunachal Pradesh, Haryana.

\section{Subfamily: Hemiacridinae Dirsh,1956}

\section{Hieroglyphus banian (Fabricius, 1798)}

Diagnostic characters: Green including the antennae. Pronotum smooth with four sulci, narrowly lined with black, the first obsolete above, the second on the sides and the last two continuous. Tegmina 
subhyaline, densely reticulated and greenish at the base, with green nervures, wings as long as the tegmina, greenish hyaline. The three sub-terminal ventral segments with silky tufts of hair on the middle. Hind tibiae blue with black tipped spines. Antennae with the basal joint yellowish-green, the rest dark green tipped with yellow.

Material examined: 1 female, 18.vi.2009, on paddy, Jehanabad.

Morphometry: (length in mm). Female: Body 49.0, Tegmina 33.1, Hind femur 23.9, Pronotum 9.4.

Natural enemies: The authors found small reddish mites possibly Trombidium sp. on adults but doubted whether they caused any mortality. $15 \%$ of egg pods dug up near Bangalore was parasitized by Scelio hieroglyphi (Basa, 1953). Many vertebrates including frogs, snakes, lizards, birds and mammals occasionally feed on H. banian but none is regarded as an important predator.

Remarks: The specimen was collected from paddy.

Distribution: West Bengal, Andhra Pradesh, Sikkim, Himachal Pradesh, Bihar, Orissa, Rajasthan, Maharashtra, Tamil Nadu, Uttar Pradesh.

\section{Spathosternum prasiniferum (Walker, 1871)}

Diagnostic characters: Small, green, integument finely rugose almost smooth. Head conical, fastigium of vertex obtusely angular or parabolic. Filiform antennae, frontal ridge narrow and sulcated. Two broad blackish band or dark greenish-band running behind the lower part of the eyes and below the lateral carinae of the pronotum which is banded above by a narrow pale yellow line and lateral carinae present, Prosternal process large, strongly, antero-posteriorly compressed, spathulated, inclined backwards.

Material examined: 2 females, 9.vii.2009, on roadside grasses, Sitamarhi; 1 male, 1 female, 19.vi.2009, on paddy, Bihar Sharif, Nalanda; 2 females, 7.vii.2009, on grasses, Muzaffarpur; 2 females, 5.vii.2009, on grasses, Darbhanga; 2 females, 24.vi.2009, on paddy, Banka; 1 female, 23.vi.2009, on grasses, Khagaria; 1 female, 16.vi.2009, on paddy, Gaya; 1 female, 9.vi.2009, on paddy, Patna; 2 females, 29.x.2010, on grasses, Buxar; 1 female, 2males, 27.x.2010, on grasses, Hajipur, Vaishali; 3 males, 26.x.2010, on grasses, Samastipur; 1 male, 4.vi.2010, on grasses, Bettiah, Pascim Champaran; 3 females, 28.x.2010, on grasses, Supaul; 1 female, 8.vi.2009, on grasses, Begusarai; 4 females, 7.vi.2009, on grasses, Luckeesarai.

Morphometry: (length in mm). Male: Body 17.5, Tegmina 12.8, Hind femur 8.65, Pronotum 2.85. Female: Body 19.2, Tegmina 14.5, Hind femur 9.65, Pronotum 3.0.

Remarks: This species is generally found on either side of road, in pastures and in crop fields. It is a pest of crop.

Natural enemies: No natural enemies recorded.

Distribution: West Bengal, Andhra Pradesh, Arunachal Pradesh, Bihar, Goa, Himachal Pradesh, Jammu \& Kashmir, Karnataka, Kerala, Madhya Pradesh, Maharashtra, Orissa, Rajasthan, Tamil Nadu, Uttar Pradesh.

\section{Subfamily: Eyprepocnemidinae Brunner, 1893 11. Eyprepocnemis alacris (Serville, 1838)}

Diagnostic characters: This is a typical species of the genus. It can easily be separated from other members of genus in having bluish grey hind tibia with two whitish signs at the base and reddish apex and tarsus, male cercus gradually narrowing towards apex incurved and down curved. Fastigium of vertex round, frontal ridge with characteristic dark brown markings on lateral carinae, prosternal process cylindrical and antero-posteriorly compressed. Elytra and wings fully developed, elytra with numerous brown spots, bluish grey hind tibiae.

Material examined: 1 female, 21.vi.2009, on maize, Jamui; 1 female, 18.vi.2009, on bushes, Jehanabad.

Morphometry: (length in mm). Female: Body 40.25, Tegmina 30.8, Hind femur 20.35, Pronotum 6.55 .

Remarks: This species is widely distributed in India and adjacent countries. It is a polyphagous species.

Natural enemies: No natural enemies are recorded.

Distribution: Tamil Nadu, Uttar Pradesh, Assam, Manipur, Meghalaya, Kerala, Andhra Pradesh, Bihar.

\section{Subfamily: Calliptaminae Brunner, 1983}

\section{Acorypha glaucopsis (Walker, 1870)}

Diagnostic characters: Body of medium size; integument finely dotted, antennae filiform, shorter than head and pronotum together, fastigium of vertex moderately long, with longitudinal concavity and strong lateral carinulae, frons vertical, frontal ridge 
flat, Lower inner spur of hind tibia with the apex simply recurved bearing sparse hairs, Pronotum with metazona slightly longer than prozona; prosternal process slightly transverse.

Material Examined: 6 males, 4 females, 13.vi.2009, on hilly grasses of Chand Tan Shahid Pir, Sasaram, Rohtas.

Morphometry: (length in mm). Male: Body 16.0, Tegmina 12.5, Hind femur 9.35, Pronotum 3.3. Female: Body 24.0, Tegmina 20.7, Hind femur 14.4, Pronotum 5.65.

Remarks: Very active and has exceptionally robust hind femur.

Natural enemies: No natural enemies recorded.

Distribution: Bihar, Rajasthan, Tamil Nadu.

\section{Subfamily: Romaleinae Roberts, 1941}

\section{Teratodes monticollis (Gray, 1832)}

Diagnostic characters: Body of medium size; antennae filiform, much shorter than head and pronotum together, head broad, fastigium of vertex rounded, frontal ridge sulcate, much widened between antennae, pronotum much compressed, forming a high crest, covering the head anteriorly and half of abdomen posteriorly, never crossed by transverse sulci, lateral carinae absent, prosternal process short, straight, apex pointed, mesosternal interspace open, tegmina and wings developed, tegmino-alar stridulatory mechanism present, hind femur short, stout, tuberculate, lower basal lobe about as long as upper one, hind tibia without external apical spine.

Material examined: 1 female, 19.vi.2009, on dead fallen leaves of forest, Rajgir, Nalanda.

Morphometry: (length in $\mathrm{mm}$ ). Female (Nymph): Body 28.15, Hind femur 12.15, Pronotum 17.15.

Remarks: Exceptionally high, raised collar like pronotum.

Natural enemies: No natural enemies recorded.

Distribution: Bihar, Uttar Pradesh, Maharashtra, Gujrat, Tamil Nadu.

\section{Subfamily: Catantopinae Brunner, 1893}

\section{Catantops pinguis innotabilis (Walker, 1870)}

Diagnostic characters: Reddish-brown, rather stout. Frontal ridge finely punctured, slightly expanded between the antennae, lateral carinae, distinct, slightly divergent, antennae filiform, Pronotum closely punctured, obtusely angulated behind, carina slight, continuous, with the sulci well marked. Abdomen with a short narrow dorsal stripe behind. Hind femora stout, with two transverse black spots above, the first extending into the externo-median area, the lower outer area blackish-brown and the upper carinae slightly serrated, hind tibiae and tarsi red, the former with black tipped spines. Cerci of the male slightly expanded at the tips. The species is easily identified by the cercus which is up curved, more broadened apex and projecting, upper apical angle is more projecting. The species is also easily identified by the character of the hind femur.

Material examined: 1 male, 26.vi.2009, Bushes and wild vegetation, Bhagalpur.

Morphometry: (length in mm). Male: Body 29.9, Tegmina 24.1, Hind tibia 13.0, Pronotum 5.65.

Remarks: C.pinguis innotablis is widely distributed in Indian subcontinent and is commonly found in shrubs and herbs.

Natural enemies: In Thailand adults are affected by the fungus Entomophthora grylli Fres. (Roffey 1965). Red mite Eutrombidium trigonum also observed parasitizing this species.

Distribution: Orissa, Goa, Uttar Pradesh, Tamil Nadu, Bihar.

\section{Xenocatantops karnyi (Kirby, 1910)}

Diagnosis: Body of medium size, antennae slightly longer or shorter than head and pronotum together, fastigium of vertex with slightly raised carinulae between eyes, median carina never strongly raised, frontal ridge never projecting between antennae, tegmina reaching beyond apex of abdomen, tegmina and wings fully developed, pronotum at least slightly constricted in middle, prosternal process conical.

Material examined: 1 female, 26.vi.2009, on arhar, Katihar.

Morphometry: (length in mm). Female: Body 31.45, Tegmina 25.65, Hind femur 14.1, Pronotum 5.9 .

Remarks: Differs from Catantops Schaum in having constricted pronotum in the middle.

Natural enemies: No natural enemies recorded.

Distribution: Bihar.

\section{Subfamily: Cyrtacanthacridinae Uvarov, 1923 \\ 16. Schistocerca gregaria Stal, 1873}

Diagnostic characters: Body of large size, 
integument finely punctuate, antennae filiform, shorter than head and pronotum together; fastigium of vertex trapezoidal, with shallow longitudinal depression, frontal ridge low, narrower than interocular distance, pronotum constricted, crossed by three transverse sulci, median carina low, sometimes indistinct in prozona, lateral carinae absent, metazona about as long as prozona, posterior margin rounded, prosternal process cylindrical, moderately bent towards mesosternum but not touching it, tegmina fully developed, apex obliquely rounded, veinlets in the apical part more or less perpendicular to the veins, hind femur with lower basal lobe shorter than upper, external apical spine of hind tibia absent.

Material Examined: 2 females, 1 male, 18.vi.2009, on maize, Jehanabad; 2 females, 1 male, 16.iv.2010, harvested wheat field, Araria.

Morphometry: (length in mm). Male: Body 47.15, Tegmina 38.5, Hind femur 21.15, Pronotum 9.0. Female: Body 67.0, Tegmina 52.8, Hind femur 30.65, Pronotum 13.4.

Remarks: Well reputed for gregaration in superfamily Acridoidea.

Natural enemies: No natural enemies recorded.

Distribution: Bihar, Uttar Pradesh.

\section{Chondacris rosea (De Geer, 1773)}

Diagnostic characters: Body of large size, integument strongly granulose, antennae filiform, longer than head and pronotum together, fastigium of vertex trapezoidal, frontal ridge slightly narrowed at apex, Pronotum tectiform, crossed by three transverse sulci, median carina raised, lateral carinae absent, Prosternal process large, strongly bent towards mesosternum, nearly touching it, mesosternal interspace open, lobes rectangular. Supra anal plate weakly trilobite, cercus compressed, apex slightly attenuate and incurved, subgenital plate elongate, acutely conical, Epiphallus bridge undivided, ancorae absent, lophi broadly triangular. Ovipositor valves comparatively slender, with curved apices, ventral valve with angular lateral projection on outerside.

Material Examined: 1 male, 2 females, 17.iv.2010, on arhar, Araria.

Morphometry: (length in $\mathrm{mm}$ ). Male: Body 67.7, Tegmina 51.75, Hind femur 32.7, Pronotum 16.2. Female: Body 91.3, Tegmina 69.45, Hind femur 43.85, Pronotum 22.6.
Remarks: Sampled from arhar field.

Natural enemies: No natural enemies recorded.

Distribution: Meghalaya, Bihar.

\section{Cyrtacanthacris tatarica tatarica (Linnaeus, 1758)}

Diagnostic characters: Body large, integument slightly granulose and punctuate-dotted, antennae filiform, about as long as head and pronotum together, pronotum moderately tectiform and slightly constricted, crossed by three transverse sulci, median carina low, lateral carinae absent, prosternal process large, widened in middle and gradually narrowing towards subacute apex. Supra anal plate slightly trilobite, with angular apical lobes, cercus compressed, sub conical, apex subacute. Subgenital plate elongate, acutely conical, female subgenital plate with posterior margin having a conical projection medially.

Material Examined: 2 males, 2 females, 17.iv.2010, on arhar, Araria.

Morphometry: (length in mm). Male: Body 52.0, Tegmina 41.25, Hind femur 25.75, Pronotum 9.7. Female: Body 61.7, Tegmina 45.6, Hind femur 29.65, Pronotum 12.5.

Remarks: Sampled from arhar field.

Natural enemies: No natural enemies recorded.

Distribution: Bihar.

\section{Subfamily: Tropidopolinae Jacobson, 1902 \\ 19. Tristria pulvinata (Uvarov, 1921)}

Diagnostic characters: Prosternal tubercle is strongly bent backward, Lower surface very broad, concave, trapezoidal with lateral margins raised and hind margin lying on mesosternum. Elytra not reaching the apex of abdomen, wings fully developed.

Material Examined: 4 females, 13.vi.2009, on grasses, Sasaram, Rohtas; 1 male, 2 females, 29.vi.2009, grasses around mango orchard, Madhubani; 2 females, 28.vi.2009, on paddy, Kishanganj.

Morphometry: (length in mm). Male: Body 29.75, Tegmina 18.55, Hind femur 15.25, Pronotum 4.35. Female: Body 48.0, Tegmina 25.1, Hind femur 19.8, Pronotum 5.5

Remarks: The species is graminivorous. It is a grassland species and is found in many species of grasses.

Natural enemies: No natural enemies recorded.

Distribution: West Bengal, Andhra Pradesh, 
Assam, Bihar, Karnataka, Maharashtra, Tamil Nadu, Uttar Pradesh.

\section{Tropidopola longicornis (Fieber, 1853)}

Diagnostic characters: Head conical, not longer than the length of pronotum, prosternal process with apical posterior margin excurved, tegmina and wings fully developed reaching tip of abdomen, Pronotum cylindrical or sub cylindrical, without lateral carinae, fastigium of vertex at most as long as longest diameter of eye.

Material Examined: 1 male, 10.vii.2009, on paddy, Siwan.

Morphometry: (length in mm). Male: Body 51.35, Tegmina 37.85, Hind femur 18.35, Pronotum 7.0.

Remarks: Collected from paddy field.

Natural enemies: No natural enemies recorded. Distribution: Bihar, Punjab, Uttar Pradesh.

\section{Family: Acrididae Latreille, 1802} Subfamily: Acridinae Latreille, 1802

\section{Acrida exaltata (Walker, 1859)}

Diagnostic characters: Head conically ascending. Fastigium broad, laminate and truncate at apex. Transverse sulcus of pronotum present about the middle of pronotal disc. Male subgenital plate comparatively long. Tegmina a little produced beyond the hind knee and wings slightly shorter than tegmina.

Materials examined: 2 females, 3 males, 26.vi.2009, on paddy, Katihar; 1 female, 27.vi.2009, on paddy, Purnia; 2 females, 1 male, 4.vii.2009, on underlying grasses in vegetable field, Saharsa; 2 females, 7.vii.2009, on grasses, Muzaffarpur; 1 male, 10.vii.2009, on paddy, Siwan; 4 males, 24.vi.2009, on paddy, Banka; 1 male, 4.vi.2010, on grasses, Bettiah, Pascim Champaran; 1 female, 1 male, 28.x.2010, on grasses, Supaul; 1 female, 29.x.2010, on grasses, Buxar; 2 females, 2 males, 9.vi.2009, on paddy, Patna; 1 male, 26.x.2010, on grasses, Samastipur; 1 female, 8.vi.2009, on grasses, Begusarai; 1 female, 6.vi.2010, on paddy, Ara, Bhojpur; 6 females, 5.vi.2010, on paddy, Madhepura.

Morphometry: (length in mm). Male: Body 52.8, Tegmina 44.8, Hind femur 31.4, Pronotum 6.8. Female: Body 48.25, Tegmina 30.0, Hind femur 24.55, Pronotum 8.2

Remarks: This species is widely distributed throughout plains and hilly regions of Indian sub- continent. It is abundantly found on grasses and paddy fields.

Natural enemies: This species was found to be parasitized by Eutrombidium trigonum.

Distribution: Very common and known from many localities in India. Sikkim, Kashmir, Himalayas, Assam, Uttar Pradesh, Bihar.

\section{Acrida gigantea (Herbst, 1794)}

Diagnostic characters: Head conically ascending. Fastigium broad, laminate and truncate at apex. Transverse sulcus of pronotum present about the middle of pronotal disc. Male subgenital plate comparatively long. Tegmina a little produced beyond the hind knee and wings slightly shorter than tegmina. Lateral carinae with black inner margins.

Material examined: 2 males, 10.vii.2009, on paddy, Siwan; 1 male, 1 female, 5.vii.2009, on grasses, Darbhanga; 2 females, 19.vi.2009, on paddy, Rajgir, Nalanda; 1 female, 4.vii.2009, on underlying grasses in vegetable field, Saharsa; 1 female, 15.vi.2009, on paddy, Gaya; 1 male, 11.vi.2009, on paddy, Bhabua, Kaimur; 1 female, 24.x.2010, on grasses, Gopalganj; 1 female, 1 male, 7.vii.2009, on grasses, Muzaffarpur; 2 females, 13.vi.2009, on paddy, Sasaram, Rohtas; 1 male, 26.vi.2009, on paddy, Katihar; 1 male, 9.vi.2009, on paddy, Patna; 1 male, 8.vi.2009, on grasses, Begusarai; 1 male, 23.x.2010, on wheat, Chhapra, Saran.

Morphometry: (length in mm). Male: Body 31.45 , Tegmina 22.0, Hind femur 17.3, Pronotum 4.3. Female: Body 50.1, Tegmina 45.65, Hind femur 31.4, Pronotum 9.65.

Remarks: Usually found in paddy and grasses and produces very striking stridulatory sound.

Natural enemies: This species was found to be parasitized by Eutrombidium trigonum.

Distribution: Bihar, Uttar Pradesh, Punjab, Haryana, Himachal Pradesh, Rajasthan, Jharkhand, Uttarakhand.

\section{Phlaeoba infumata Brunner, 1893}

Diagnostic characters: Antennae ensiform. Lateral carinae of pronotum straight, disc of pronotum rugose. Wings fusco-hyaline, infumated towards the apex. Subgenital plate of male acute.

Material examined: 1 male, 11.vi.2009, on dead vegetation, Bhabua, Kaimur; 1 female, 21.vi.2009, on 
paddy, Jamui.

Morphometry: (length in mm). Male: Body 24.65, Tegmina 17.55, Hind femur 12.05, Pronotum 3.2. Female: Body 32.1, Tegmina 23.5, Hind femur 16.4, Pronotum 5.0.

Remarks: This species occur in sugarcane fields.

Natural enemies: No natural enemies have been recorded.

Distribution: Arunachal Pradesh, Assam, Bihar, Haryana, Himachal Pradesh, Manipur, Tamil Nadu, Uttar Pradesh, West Bengal.

\section{Phlaeoba panteli (Bolivar, 1902)}

Diagnostic characters: Body slender and of moderate size, antennae ensiform, median carinula present, frons oblique, frontal ridge sulcate, median carina excised by anterior and posterior sulcus each, hind wings hyaline, lateral carinae linear.

Material examined: 1 female, 22.vi.2009, on dead vegetation, Munger.

Morphometry: (length in mm). Female: Body 29.6, Tegmina 24.0, Hind femur 16.5, Pronotum 5.6

Remarks: Usually spotted on dead and decaying plant material lying on ground.

Natural enemies: No natural enemies have been recorded.

Distribution: Uttar Pradesh, Bihar, Punjab.

\section{Subfamily: Oedipodinae Walker, 1870}

\section{Trilophidia annulata (Thunberg, 1815)}

Diagnostic characters: Small insect, antennae filiform with black yellow bands, eyes somewhat bulging, pronotum saddle shaped, median carina forming tooth like projections in prozona, apex of tegmina truncated, hind femur with a yellow band just above the basal lobe.

Material examined: 2 females, 16.vi.2009, on sugarcane, Gaya.

Morphometry: (length in mm). Female: Body 22.8, Tegmina 18.6, Hind femur 9.8, Pronotum 3.85.

Remarks: Commonly found in sugarcane and paddy.

Natural enemies: Red mite Eutrombidium trigonum was observed parasitizing this species.

Distribution: Punjab, Haryana, Rajasthan, Bihar, Jharkhand, Uttarakhand, Himachal, Arunachal Pradesh, Tripura, Meghalaya,

\section{Aiolopus simulatrix (Walker, 1870)}

Diagnostic characters: It is popularly known as Sudan Plague locust and is a serious pest of grain and many other crops. The species is variable in general coloration, size, relative length of tegmina and width of hind femur. It can easily be distinguished by its broad hind femur which is longer than hind tibia and by the form of frontal ridge and pronotum.

Material examined: 3 females, 2 males, 11.vi.2009, on paddy, Bhabua, Kaimur; 6 females, 15.vi.2009, on paddy, Gaya; 3 females, 2 males, 27.vi.2009, on paddy, Purnia; 3 females, 4 males, 21.vi.2009, on paddy, Jamui; 1 female, 2 males, 22.vi.2009, on paddy, Munger; 2 males, 23.vi.2009, on paddy, Khagaria; 1 female, 6.vi.2010, on paddy, Ara, Bhojpur; 4 males, 23.x.2010, on wheat, Chhapra, Saran ; 2 females, 2 males, 28.vi.2009, on paddy, Kishanganj.

Mophometry: (length in mm). Male: Body 11.211.7, Pronotum 6.4-7.1, Tegmina 17.3-17.7 Hind femur 7.3-7.8. Female: Body 13.3-13.9, Pronotum 7.1-8.3, Tegmina -22.3-23.1, Hind Femur 11.3 11.7.

Remarks: A common pest of agricultural crops. Observed in groundnut, paddy, cholam, ragi and brinjal fields as well as grasslands.

Natural enemies: No natural enemies recorded.

Distribution: Andaman \& Nikobar Islands, Bihar, Delhi, Haryana, Himachal Pradesh, Karnataka, Madhya Pradesh, Punjab, Orissa, Rajasthan, Tamil Nadu, Uttar Pradesh, West Bengal.

\section{Aiolopus thalassinus thalassinus (Fabricius, 1781)}

Diagnostic characters: Medium sized insect, tegmina and wings fully developed, head acutely conical, antennae filiform, as long as or longer than head and pronotum together, fastigium of vertex elongateangular, slightly concave, with well developed lateral carinulae, frons oblique; frontal ridge flat, pronotum slightly tectiform and slightly constricted in prozona, median carina weak, medial area of tegmen with intercalary vein well developed and finely serrated, hind femur slender, hind tibia with inner pair of spines longer than external one, external apical spine absent, arolium of small size, Frontal ridge of uniform width with nearly parallel margins, foveolae shorter, hind tibia coloured as in tumulus but with a dark ring before the middle and without the bluish median part. 
Material examined: 1 female, 25.x.2010, on wheat, Motihari, Purba Champaran; 3 males, 23.x.2010, on wheat, Chhapra, Saran.

Morphometry: (length in mm). Male: Body 25.8, Tegmina 20.05, Hind femur 11.85, Pronotum 3.75. Female: Body 33.1, Tegmina 26.75, Hind femur 16.2, Pronotum 5.15.

Remarks: Commonly found in vegetable fields of brinjal, lady finger, tomato and also in paddy fields.

Natural enemies: Red mite identified as Eutrombidium trigonum was found to infect the insect.

Distribution: West Bengal, Bihar, Uttar Pradesh, Uttarakhand, Jharkhand, Haryana, Punjab.

\section{Aiolopus thalassinus tamulus (Fabricius, 1798)}

Diagnostic characters: Coloured in combination of black and green. Frontal ridge gradually tapered towards the fastigium, foveolae longer, hind tibia in the basal third with a straw-coloured band, in the median part usually bluish, the apical part reddish.

Material examined: 2 males, 1 female, 21.vi.2009, on paddy, Jamui; 2 females, 23.vi.2009, on paddy, Khagaria; 1 male, 22.vi.2009, on paddy, Munger; 2 females, 13.vi.2009, on paddy, Sasaram, Rohtas; 4 females, 6.vi.2010, on paddy, Ara, Bhojpur.

Morphometry: (length in mm). Male: 24.4, Tegmina 18.2, Hind femur 8.2, Pronotum 3.4. Female: 33.5, Tegmina 26.9, Hind femur 15.2, Pronotum 4.75.

Remarks: Common in paddy fields but may also be encountered in wheat, maize, and grassland areas surrounding the fields.

Natural enemies: No natural enemies recorded.

Distribution: Bihar, Uttar Pradesh, Uttarakhand, Jharkhand, Haryana, West Bengal.

\section{Chloebora grossa (Saussure, 1884)}

Diagnostic characters: Large sized insect with nearly round eyes, Median carina well developed but lateral carinae show slight presence in metazona, tegmina membranous at apical one third part, hind wing membranous and bears a complete fascia midway, hind tibia is markedly shorter than femur.

Material examined: 1 male, 1 female, 13.vi.2009, on grasses of Chand Tan Shahid Pir, Sasaram, Rohtas

Morphometry: (length in mm). Male: Body 35.6, Tegmina 27.45, Hind femur 14.2, Pronotum 6.55. Female: Body 51.4, Tegmina 39.5, Hind femur 22.5,
Pronotum 9.4.

Remarks: It shows its presence in forest areas in and around bushes and exhibits good camouflage with the surrounding rocks.

Natural enemies: No natural enemies have been recorded.

Distribution: Bihar, Tamil Nadu.

\section{Acrotylus insubricus (Scopoli, 1786)}

Diagnostic characters: Body of medium size, pronotum saddle shaped and shorter than width, eyes somewhat bulging, tegmina with infuscated spots beyond middle, hind wings with lunate incomplete fascia.

Material examined: 1 female, 9.vii.2009, on paddy, Sitamarhi.

Morphometry: (length in mm). Female: Body 26.0, Tegmina 20.35, Hind femur 7.7. Pronotum 2.8.

Remarks: It has been found damaging rice and millet in India.

Natural enemies: No natural enemies have been recorded.

Distribution: Andhra Pradesh, Bihar, Goa, Maharashtra, Rajasthan, Tamil Nadu, Uttar Pradesh.

\section{Oedaleus senegalensis (Krauss, 1877)}

Diagnostic characters: A characteristic X mark on the Pronotum, which is broadly rounded posteriorly. Hind wing, yellow basally with complete dark fascia.

Material examined: 1 male, 1 female, 20.vi.2009, on paddy, Nawada.

Morphometry: (length in mm). Male: Body 20.45, Tegmina 15.7, Hind femur 10.2, Pronotum 3.4. Female: Body 25.8, Tegmina 19.6, Hind femur 13.2, Pronotum 4.25.

Remarks: Widely distributed in Indian subcontinent.

Natural enemies: No natural enemies recorded.

Distribution: Andhra Pradesh, Bihar, Himachal Pradesh, Jammu and Kashmir, Karnataka, Madhya Pradesh, Meghalaya, Orissa, Rajasthan, Tamil Nadu, Uttar Pradesh, West Bengal.

\section{Oedipoda miniata (Pallas, 1771)}

Diagnostic characters: Wings mostly rugose so the dark band often pale brown, strongly bowed reaching upto IXth or Xth section of anal fan and not touching hind margin (Harz 1975). Integument often 
less rugose and less callous. Facial carinula mostly without projections. Dark fasciae of wings extending towards the base by one longitudinal band into the anterior field.

Material examined: 1 female, 14.vi.2009, on arhar, Aurangabad; 2 females, 20.vi.2009, on maize, Nawada; 2 females, 21.vi.2009, on sugarcane, Jamui.

Morphometry: (length in $\mathrm{mm}$ ). Female: Body 45.55, Tegmina, 36.0, Hind femur, 20.7, Pronotum 9.6 .

Remarks: This species can be easily distinguished from O. coerulescens (Linnaeus, 1758) because its wings are basally red.

Natural enemies: No natural enemies recorded.

Distribution: Uttar Pradesh, Bihar, Punjab, Himachal Pradesh, Rajasthan.

\section{Locusta migratoria (Linnaeus, 1758)}

Diagnostic characters: It occurs in green and brown form in the solitary phase. The species can easily be identified from other Locusts by the absence of prosternal process, the slight yellow tinting of the wings and the black anal veins are distinctive features of the species.

Material examined: 1 male, 11.vi.2009, on arhar, Bhabua, Kaimur; 1male, 2 females, 27.vi.2009, on paddy, Araria; 2 females, 27.vi.2009, on paddy, Purnia.

Morphometry: (length in mm). Male: Body 44.85, Tegmina 37.65, Hind femur 20.15, Pronotum 7.77. Female: Body 60.4, Tegmina 48.8, Hind femur 25.6, Pronotum 10.0.

Remarks: Though quite strict graminivorous and capable of causing considerable damage to grain crops, very many plants belonging to different families have been recorded as food.

Natural enemies: It is sometimes heavily infested with mites.

Distribution: Assam, Bengal, Kashmir, South India, Bihar, Uttar Pradesh, Himachal Pradesh, West Bengal, Maharashtra.

\section{Subfamily: Truxalinae Walker, 1870}

\section{Truxalis nasuta (Linnaeus, 1758)}

Diagnostic characters: The species can easily be identified by its pronotum sellate, hind wing strongly dark brown tessellate, basally crimson in female.

Material Examined: 1 female, 21.vi.2009, on paddy, Jamui.

Morphometry: (length in mm). Female: Body 67, Tegmina 61, Pronotum 7, Hind femur 45.

Remarks: Graminivorous. It is usually found in old farmland. Also found in sparse gramineous vegetation and some occur even in cultivated fields.

Natural enemies: No natural enemies have been recorded.

Distribution: Rajasthan, Bihar, Uttar Pradesh, Punjab.

\section{Subfamily: Gomphocerinae Jacobson \& Blanki, 1902}

\section{Chorthippus indus (Uvarov, 1942)}

Diagnostic characters: Colour variable, green, testacious or brown. Antennae sub depressed, longer than the head and pronotum together. Pronotum with transverse sulcus placed about the middle, the head not carinated above, the pronotum strongly tricarinate, the median carina slightly raised, the lateral carinae slightly incurved before the middle and then diverging. Tegmina longer than abdomen in a male usually shorter in the female, sometimes with longitudinal yellow scapular lines. Wings hyaline with brown nervures. Pectus and front leg pilose, legs not spotted, hind tibia with twelve small spines, decreasing in size towards the base. Subgenital plate in the male is curved, pubescent, valves of the ovipositor unarmed.

Material examined: 1 male, 29.vi.2009, on grasses of vegetable field, Madhubani.

Morphometry: (length in mm). Male: Body 17.15, Tegmina 11.7, Hind femur 10.6, Pronotum 3.7.

Remarks: It is a large species other than those already recorded. It may well become minor pests at times.

Natural enemies: No natural enemies have been recorded.

Distribution: Jammu and Kashmir, Uttar Pradesh, Punjab.

\section{Leva indica (I. Bolivar, 1902)}

Diagnostic characters: Testacious varied with brown faveolae of the vertex subquadrate, filled up with black frontal carina impress punctuate, sulcate at the ocellus for a large space in the male, a short space in the female. Antennae filiform, slightly depressed. Pronotum pale above. Tegmina subhyaline with a yellow spacular line and brown discoid spots. Hind 
femora with four brown bands, often obsolete on the outer side.

Material examined: 1 female, 4.vii.2009, on paddy, Saharsa.

Morphometry: (length in mm). Female: Body 17.5, Tegmina 12.95, Hind femur 9.4, Pronotum 2.75.

Remarks: It is very small species. Lateral carinae of pronotum parallel in prozona and strongly divergent in metazona which is the most characteristic feature of the species. Abundantly found on grasses and paddy crops.

Natural enemies: No natural enemies are recorded.

Distribution: West Bengal, Delhi, Tamil Nadu, Tripura, Uttar Pradesh.

\section{Leionotacris bolivari (Uvarov, 1921)}

Diagnostic characters: Frontal ridge convex; fastigial foveolae elongate rhomboidal, dorsum of head and pronotum with a pale stripe extending from anterior margin of fastigium to posterior margin of pronotum with posterior transverse sulcus placed in the middle, tegmina perfectly developed at least reaching tip of hind femur with three dark spots on radial area.

Material examined: 1 female, 14.vi.2009, on lady finger, Aurangabad.

Morphometry: (length in mm). Male: Body 10.8, Pronotum 5.7, Tegmina 15.1, Hind Femur 10.7.

Remarks: This species has been recorded as a minor pest on the foliage of teak in India.

Natural enemies: No natural enemies have been recorded.

Distribution: West Bengal, Assam, Bihar, Himachal Pradesh, Madhya Pradesh, Maharashtra, Sikkim, Karnataka and Uttar Pradesh.

\section{REFERENCES}

Agarwala, S.B.D. (1952). A comparative study of the ovipositor in the Acrididae - I. Indian Journal of Entomology, I 13: 147-181.

Agarwala, S.B.D. (1952). A comparative study of the ovipositor in the Acrididae - I. Indian Journal of Entomology, II 14: $61-75$.

Bhowmik, H.K. (1985). Outline of distribution with an indexCatalogue of Indian grasshoppers (Orth.: Acrididae). Part I. Acridinae, Truxalinae, Gomphocerinae and Oedipodinae. Records of Zoological Survey of India Miscellaneous Publication Occasional Paper 78: 1-51.

Dey, A. \& A.K. Hazra (2003). Diversity and distribution of grasshopper fauna of Greater Kolkata with notes on their ecology. Memoirs 19(3): 1-118.

Dirsh, V.M. (1965). The African Genera of Acridoidea. AntiLocust Research Centre and Cambridge University Press, London, 579pp.

Dirsh, V.M. (1975). Classification of Acridomorphoid Insects. Faringdon, Oxon, E.W. Classey, 171pp.

Hazra, A.K., S.K. Tandon, M.S. Shishodia, A. Dey \& S.K. Mandal (1993). Insecta: Orthoptera: Acridoidea. In: Fauna of West Bengal, State Fauna Series 3(4): 287-354.

Julka, J.M., S.K. Tandon, P. Halder \& M.S. Shishodia (1982). Ecological observation on grasshoppers (Orthoptera: Acridoidea) at Solan, Himachal Pradesh, India. Oriental Insects 16: 63-75.

Kirby, W.F. (1914). The Fauna of British India, Including Ceylon and Burma. Orthoptera (Acrididae). Taylor and Francis, London, ix+276pp.

Kumar, P. \& C.A. Viraktamath (1991a). Illustrated keys for identification of common species of short-horned grasshoppers (Orthoptera: Acridodea) of Karnataka and short notes on their ecology and behaviour. Hexapoda 3(12): $53-70$.

Kumar, P. \& C.A. Viraktamath (1991b). Taxonomic significance of the male genitalia (Epiphallus) of some species of Short-horned Grasshoppers (Orthoptera: Acridoidea). Journal of the Bombay Natural History Society 88(2): 200-209.

Nayeem, M.R. \& M.K. Usmani (2011). Diversity of Acridoidea (Orthoptera) from southern and southwestern region of Bihar, India. Folia Heyrovskyana 19(1-4): 5-12.

Nayeem, M.R. \& M.K. Usmani (2012). Taxonomy and Field Observations of Grasshopper and Locust Fauna (Orthoptera: Acridoidea) of Jharkhand, India. Munis Entomology \& Zoology 7(1): 391-417.

Roonwal, M.L. (1956). Bibliographica Acrididorum. Records of Indian Museum 56: 1-611.

Shishodia, M.S. (1987). Orthoptera Fauna of Assam. State Fauna Series (1): 91-102.

Shishodia, M.S. (1997). Orthoptera Fauna of Delhi. State Fauna Series: Zoological Survey of India 173-176pp.

Shishodia, M.S. (1999). Orthoptera fauna of Patalkot, chhindwara, Madhya Pradesh, India. Records of Zoological Survey of India 97 (4): 33-43.

Shishodia, M.S., K. Chandra \& S.K. Gupta (2010). An annotated Checklist of Orthoptera (Insecta) from India. Records of Zoological Survey of India, Occasional Paper No. 314: 1-366.

Tandon,S.K.(1975). On the genus Chondracris Uvarov(Insecta: Orthoptera: Acridoidea: Acrididae: Cyrtacanthacridinae) in India. Dr. B.S. Chauhan Commemoration Volume 395402.

Tandon, S.K. (1976). A Check-list of the Acridoidea (Orthoptera) of India Part I Acrididae. Records of Zoological Survey of India. Occasional Paper No. 3: 1-48.

Tandon, S.K. \& P. Khera (1978). Ecology and distribution of grasshoppers (Orthoptera: Acridoidea) in Arunachal 


\section{Key to tribes of the family Pyrgomorphidae Brunner, 1874}

1 Body never depressed; prosternum without reflexed collar-like anterior margin................................................2 Body depressed; pronotum with reflexed collar-like anterior margin; tegmina with small nodules on main veins; antennae cylindrical ......................................................................................... Chrotogonini Bolivar, 1904

2 Body small, never large and heavy; tegmina and hind wing usually fully developed......................................... Body large and heavy; antennae filiform with basal segments as long as wide; pronotum with metazona convex, much widened distally, posterior margin somewhat rounded; tegmina and hind wing well developed.....

Poekilocerini Burmeister, 1840

3 Tegmina if fully developed, never tapered and pointed; epiphallus bridge-shaped; apical part of spermatheca S-shaped ...................................................................................................... Pyrgomorphini Brunner, 1874 Tegmina usually fully developed and usually very tapered and pointed; epiphallus anchor-shaped; apical part of spermatheca with two diverticula ..................................................... Atractomorphini Bolivar, 1884

\section{Key to subfamilies of the family Catantopidae Brunner, 1893}

1 Lower knee lobe of hind femur never spined; valves of ovipositor never serrate or spined; hind tibia never flattened

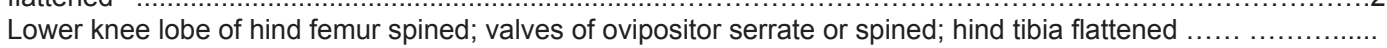
Oxyinae Brunner, 1893

2 Hind femur never much robust, usually reaching beyond apex of abdomen; epiphallus bridge shaped, ancorae usually curved, articulated with bridge, lophi present; male circus never toothed apically ................................ Hind femur much robust, never reaching beyond apex of abdomen; epiphallus disc shaped, ancorae finger shaped, articulated in the middle of the disc, lophi absent; male circus large, strong, curved and toothed apically Calliptaminae Brunner, 1893

3 Radial area of tegmen without transverse stridulatory veinlets; valves of aedeagus flexure; arolium of variable

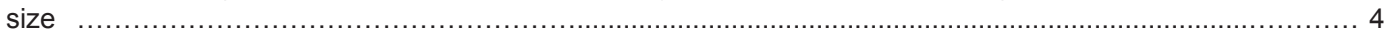
Radial area of tegmen with a series of regular, parallel, thickened, transverse stridulatory veinlets; valves of aedeagus divided or connected by small or indistinct flexure; arolium large............. Hemiacridinae Dirsh, 1956

4 Hind femur with lower basal lobe shorter than upper one; tegmino-alar stridulatory mechanism absent ..............5 Hind femur with lower basal lobe as long as upper one; tegmino-alar stridulatory mechanism present ...............

5 Mesosternal interspace open; hind femur with dorsal carina finely denticulate, sometimes smooth; external

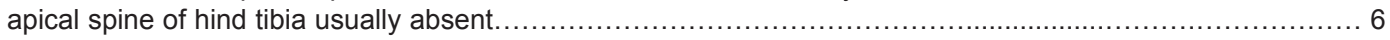
Mesosternal interspace closed; hind femur with dorsal carina smooth; external apical spine of hind tibia present . Tropidopolinae Jacobson, 1902

6 Mesosternal lobes rounded; ancorae well developed and curved; pronotum with median carina never raised;

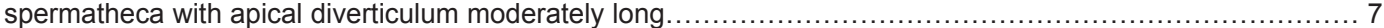
Mesosternal lobes rectangular; ancorae small or indistinct; pronotum with median carina slightly raised; spermatheca with apical diverticulum very long and slender.

7 Pronotum with lateral carinae linear; male circus strongly compressed, apex down curved .....

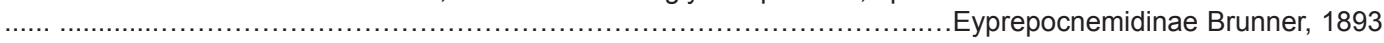
Pronotum without lateral carinae, if present, never linear; male circus variable, never strongly compressed, apex normal .Catantopinae Brunner, 1893

Pradesh, India and impact of human activities on their ecology and distribution. Memoirs of the School of Entomology 6: 73-92.

Usmani, M.K. (2006). Taxonomic significance of female subgenital plate in some Indian grasshoppers (Orthoptera : Acridoidea). Sebha University Journal 4(1): 51-66.

Usmani, M.K. \& S.A. Shafee (1980). Female genitalia in some India species of Pyrgomorphinae (Orthoptera : Acrididae). Journal of Entomological Research (4): 41-44.

Usmani, M.K. \& S.A. Shafee (1982). Taxonomic significance of ovipositor in some Indian grasshoppers (Orthoptera: Acrididae). Journal of the Bombay Natural History Society 79(3): 576-580.

Usmani, M.K. \& S.A. Shafee (1983). A new genus and two new species of the subfamily Acridinae (Orthoptera: Acrididae) from India. Bulletin of Swiss Entomological Society 56: 401-403.

Usmani, M.K. \& S.A. Shafee (1984). A new tribe of Oxyinae (Orthoptera: Acrididae). Bulletin of Swiss Entomological Society 57: 295-296.

Usmani, M.K. \& S.A. Shafee (1985a). A new species of the genus Ramakrishnaia I. Bolivar (Orthoptera : Pyrgomorhidae) from India. International Journal of Entomology 27(3): 204-207.

Usmani, M.K. \& S.A. Shafee (1985b). A revision of the Indian species of Oxya (Oxyinae: Acrididae). Oriental Insects 19: 311-322.

Usmani, M.K. \& S.A. Shafee (1990). Classification of Indian 


\section{Key to subfamilies of Acrididae Latreille, 1802}

1 Stridulatory serration on inner side of hind femur absent. 2 Stridulatory serration on inner side of hind femur present.......

2 Body usually slender; frons oblique; medial area of tegmen usually without intercalary vein, if present, never serrated in both sexes................................................................................ Acridinae Latreille, 1802 Body rather sturdy; frons usually vertical; medial area of tegmen with intercalary vein usually serrated

Oedipodinae Scudder, 1875

3 Body very slender; antennae flattened, ensiform; eyes nearer to apex of head than to its base; hind femur long and narrow, its stridulatory file represented by closely set rigid tubercles and articulated bristles

Truxalinae Walker, 1870

Body moderately slender; antennae normally filiform but tend to be compressed and ensiform in species with elongated body; eyes never nearer to apex of head than to its base; hind femur never extremely narrow, its stridulatory file with articulated pegs..... Gomphocerinae Hebard, 1935

Acrididae (Orthoptera: Acridoidea). Indian Journal of Systematic Entomology $7(2): 89-102$.

Uvarov, B.P. (1921). Notes on Orthoptera in the British Museum. I. The group Euprepocnemini. Transactions of Entomological Society of London 106-144.

Uvarov, B.P. (1924). A revision of the old world Cyrtacanthacrini, Annual Magazine of Natural History 13(9): 1-19.

Uvarov, B.P. (1927). Distributional records of Indian Acrididae. Records of Indian Museum 29: 233-239.

Uvarov, B.P. (1942). Differentiating characters of Oedipodinae and Acridinae. Transactions of American Entomological Society 67: 303-361.

Uvarov, B.P. (1966). Grasshoppers and Locusts. A Hand book of General Acridology. Cambridge, $\mathrm{XI}+481 \mathrm{pp}$.
Author Details: Dr. MoHD. KAMIL Usmani presently engaged as Associate Professor at Department of Zoology, A.M.U., Aligarh. Ph.D. (1982) from the same institution and Post-graduate Diploma in Applied Insect Taxonomy \& Biological Control (1985) from Cardiff University, Cardiff, U.K. Has teaching experience of 28 years and research experience of 34 years and has published about 63 research papers and three books. Has successfully completed three major research projects in India as well as abroad.

MD. RASHID NAYEEM presently engaged as JRF on Major Project of MoEF and Research Scholar at Department of Zoology, A.M.U., Aligarh. Obtained M.Sc. (2008) degree from the same Institution. Worked as Junior Research Fellow for two years and Senior Research Fellow for one year on DST sponsored Major Research Project. Ten research papers have been published and three are accepted for publication. 